\title{
MICROSURGICAL TRANSFER OF THE GRACILIS MUSCLE FOR ELBOW FLEXION IN BRACHIAL PLEXUS INJURY IN ADULTS: RETROSPECTIVE STUDY OF EIGHT CASES
}

Luiz Koiti Kimura' ${ }^{1}$ Alexandre Tadeu do Nascimento², Roberto Capócio², Rames Mattar Junior ${ }^{3}$, Marcelo Rosa Rezende', Teng Hsiang Wei ${ }^{1}$, Luciano Ruiz Torres' ${ }^{1}$, Fernando Munhoz Moya ${ }^{4}$

\section{ABSTRACT}

Objective: Treating brachial plexus injuries is a major challenge, especially lesions that are presented late, with more than 12 months of evolution. We retrospectively analyzed patients who underwent one of the possibilities for attempting to restore the function of upper limbs affected under such conditions: microsurgical transfer of the gracilis muscle for elbow flexion. Methods: Eight patients were included, divided into two groups: one in which the procedure consisted of neurorrhaphy of the muscle flap with sural nerve grafting and anastomosis more distally; and the other, in which the neurorrhaphy was performed directly on the spinal accessory nerve, with anastomosis in thoracoacromial vessels. Results: We found a significant difference between the groups. A greater number of satisfactory results (75\% M4) were found among patients who underwent direct neurorrhaphy, whereas the procedure using grafts for neurorrhaphy was less successful ( $25 \% \mathrm{M} 4)$. Conclusion: Patients who underwent microsurgical functional transfer of the gracilis muscle in which vascular anastomoses were performed in thoracoacromial vessels presented better functional outcomes than shown by those whose anastomoses were in the brachial artery with subsequent use of a nerve graft.

Keywords - Brachial Plexus; Microsurgery; Elbow

\section{INTRODUCTION}

Treatments for patients with brachial plexus lesions have improved consequent to innovations in reconstructions of the nerves in the initial stages after the trauma. However, difficulty in treating patients more than 12 months after the accident, or in cases with pre-ganglionic lesions, continues to exist.

One of the possible causes of failure in peripheral nerve reconstructions beyond this time limit is failure of the plate between the nerve and the muscle. In fact, Azze et $a l^{(1)}$ reported that patients operated more than nine months after the trauma presented recovery that was significantly worse than among those operated before this time.

Patients who present partial paralysis can be treated with muscle transfers even after passing this time limit: the initial function of the muscle is partially or totally lost but the priority function is recovered. According to Narakas ${ }^{(2)}$, elbow flexion is the most important movement to be recovered in the upper limbs and is the first priority in treating brachial plexus lesions.

Patients who present total paralysis of the upper limbs cannot benefit from this treatment, because they do not have any musculature that can be transferred.

\footnotetext{
1 - Attending Physician in the Hand Group, Institute of Orthopedics and Traumatology, HC/FMUSP, São Paulo, SP, Brazil.

2 - Resident Physician, Institute of Orthopedics and Traumatology, HC/FMUSP, São Paulo, SP, Brazil.

3 - Associate Professor in the School of Medicine, USP; Head of the Hand Group, Institute of Orthopedics and Traumatology, HC/FMUSP, São Paulo, SP, Brazil.

4 - Collaborating Physician in the Hand Group, Institute of Orthopedics and Traumatology, HC/FMUSP, São Paulo, SP, Brazil.

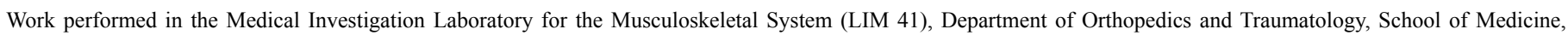
University of São Paulo.

Correspondence: Alexandre Tadeu do Nascimento, Rua Dr. Ovídio Pires de Campos 333, Cerqueira Cesar, 05403-010, São Paulo, SP. E-mail: jangadamed@hotmail.com Work received for publication: August 13, 2010; accepted for publication: September 16, 2010.
} 
In the 1980s, many transfer techniques for peripheral nerves were described. Transfer of the accessory nerve, as described by Brunelli ${ }^{(3)}$, opened up a range of possibilities for functional recovery among patients with brachial plexus lesions. Use of intercostal nerves and even nerves of the contralateral plexus has been described, but all of these possibilities have limited use in patients for whom more than around one year elapsed between the trauma that triggered the lesion and the date of the operation. Muscle or motor end plate degeneration was responsible for lack of success in this type of treatment.

One logical solution is to use a healthy muscle, without degeneration, to function as a recipient for these transferred nerves. Microsurgical transfer of muscles, transplanted together with their vessels and nerves, is use to cover areas with major exposure. Reinnervation of these muscles by transferring local nerves that will function as donors seems to be the solution for the obstacle created through degeneration of the neuromuscular plate. Ikuta et $a l^{(4)}$ described functional microsurgical transplantation of muscles, which is a new possibility for such patients to recover movement.

One of the techniques that have been described consists of constructing a functional microsurgical flap from the gracilis muscle, in order to recover elbow flexion (Figures 1 and 2). Doi et $a l^{(5)}$ described the possibility of making this transfer, and its results have been reproduced in several centers with a mean success rate of between 65 and $96 \%$, according to Adams et $a l^{(6)}$.

Although this procedure is technically very demanding, it can be carried out in hospitals that have capacitation to perform microsurgery and reimplantation.

Like in all new procedures, there are debates about certain aspects of the surgical tactics. In the particular case of microsurgical transfer of the gracilis muscle, there are several controversies and they are all related to each other in some way. One of them relates to the fixation method for the proximal part of the gracilis muscle.

Some authors have preferred that the proximal insertion should be made in the clavicle ${ }^{(6-8)}$, coracoid process or even in the ribs ${ }^{(9)}$. According to the place where this insertion is made, the site

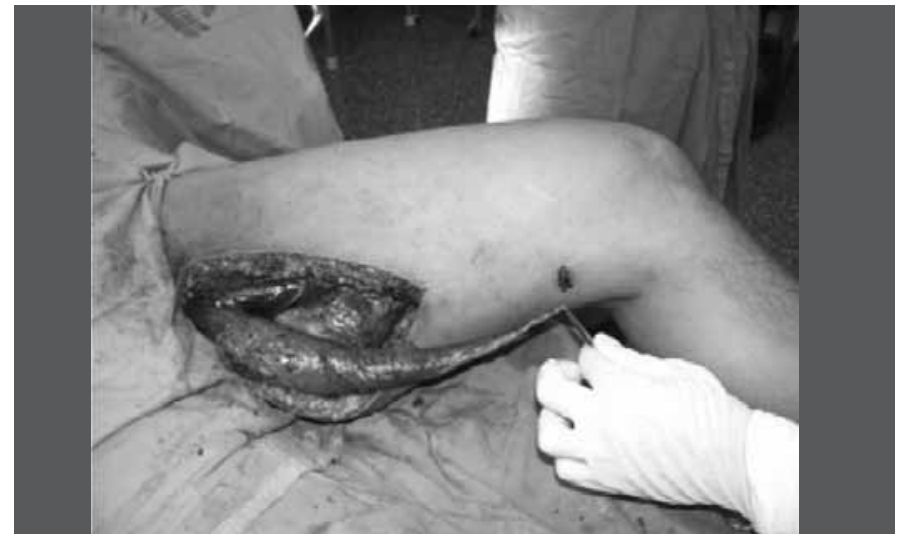

Figure 1 - Removal of flap from gracilis.

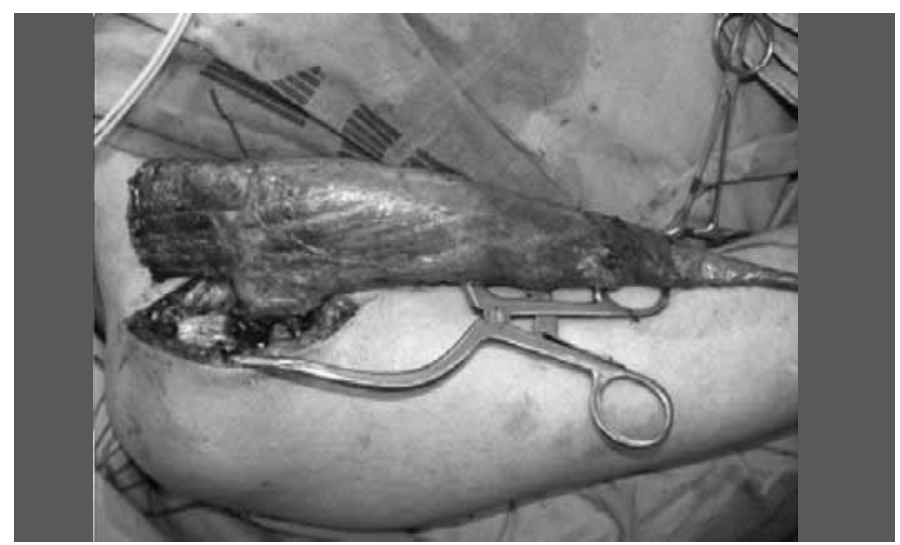

Figure 2 - Gracilis flap for insertion.

of the arterial anastomosis and donor nerve will also need to be changed.

When the origin of the transferred gracilis is more distal, the anastomosis should be made in the brachial artery, consequently increasing the need to use a graft in order to perform neurorrhaphy between the donor nerve and the nerve of the gracilis muscle.

Initially, in the hospital where the work was conducted, both the arterial anastomosis and the microneurorrhaphy were performed distally, using nerve grafts. Another series was performed with anastomosis in the thoracoacromial vessels and without use of a nerve graft.

The aim of the present study was to conduct a retrospective analysis on a series of clinical cases of patients at our clinic who underwent the procedure of microsurgical transfer of the gracilis muscle in order to achieve recovery of elbow flexion, with analysis on the functional recovery that these patients achieved and correlating the anastomosis location and use/ nonuse of nerve grafts with the postoperative results. 


\section{SAMPLE AND METHODS}

In this study, only patients with chronic brachial plexus lesions were included, i.e. individuals for whom the time that had elapsed between the trauma that caused the lesion and the surgery to transfer the gracilis muscle was greater than 12 months.

The patients' medical files and data relating to identification, sex and age were analyzed, as well as the initial status of the lesion and its postoperative outcome. The medical files were divided into two groups according to the location of the anastomosis and whether a nerve graft between the donor and recipient of the gracilis muscle was used, as follows:

Group A: patients who underwent the procedure with a graft from the sural nerve used for neurorrhaphy, or with the spinal accessory nerve, or with the intercostal nerves;

Group B: patients who underwent the gracilis muscle transfer procedure with neurorrhaphy directly in the spinal accessory nerve.

We made comparisons between the two groups of patients.

The functional assessments took into account the elbow flexion strength in accordance with the criteria of the Medical Research Council, which grade muscle function from 0 to 5 , such that cases are considered to be a success if M4 or above is attained.

The medical files of 12 patients who underwent gracilis muscle transfer to restore elbow flexion were analyzed in this retrospective study. These patients were treated over the last eight years at our institution. Four medical files were excluded for the following reasons: two patients were lost from the follow-up, i.e. they did return for reassessments; one patient underwent partial transfer of the ulnar nerve; and the last of these four patients underwent proximal muscle transfer surgery of the forearm, as described by Steindler ${ }^{(10)}$.

\section{SURGICAL TECHNIQUE}

For both groups, the gracilis muscle with its neurovascular pedicle was removed in the same manner. The patient was placed in a supine position, with the lower limb abducted and rotated externally. The gracilis muscle lies superficially on the medial face of the thigh, and one important characteristic is that in this location, it is the only muscle that contracts with flexion-extension of the knee ${ }^{(8)}$, which makes it easier to identify when smaller incisions are used. The arterial supply derives from branches of the deep femoral artery, and the dominant and most-used branch is the one located most proximally, at around 8 to $12 \mathrm{~cm}$ from the muscle origin.

The motor innervation of the muscle is provided by a branch of the obturator nerve, which lies between 6 and $12 \mathrm{~cm}$ from the origin of the muscle. Its dissection can be extended in order to obtain a stump of approximately $10 \mathrm{~cm}$. After identifying this, it was deinserted proximally, in the region of the pubic symphysis, and distally, in the proximal medial region of the lower leg (pes anserinus).

In the proximal region, we generally used a skin monitor to assess the flap after the operation.

\section{Patients in group $\mathbf{A}$}

For the patients in group A, techniques both for anastomosis (anterior humeral circumflex artery or deep brachial artery) and for neurorrhaphy (spinal accessory nerve or intercostal nerves). For one patient who underwent neurorrhaphy with intercostal nerves, an inframammary incision was added, with dissection of three intercostal nerves. For the other patients, the incision was deltopectoral with an extension more proximally in order to dissect the spinal accessory nerve (distal branch) in the supraclavicular region, which was found in the anterior portion of the trapezius muscle and confirmed using an intraoperative electrical stimulation test. The patients in this group also required an approach in the lower leg in order to collect the sural nerve for grafting, through several small transverse incisions in the lateral face of the leg. Fibrin glue was used as an aid in the neurorrhaphy.

Within this group, there was also differentiation between types of anastomosis, such that through the same initial incision, both the anterior circumflex vessels and the deep brachial artery vessels could be reached.

\section{Patients in group B}

For the patients in group B, the technique used was direct neurorrhaphy in the spinal accessory nerve. We basically followed the same guidance for dissection as before, but with direct neurorrhaphy and, therefore, 
the flap positioning was more proximal. The vessels selected for anastomosis were the thoracoacromial vessels.

In the distal portion, the insertion of the gracilis muscle was achieved by means of Pulvertaft suturing in the tendon of the brachial biceps muscle, with the elbow kept flexed at 30 o to 450 , while maintaining the muscle tension.

The patients' medical files were analyzed and the data were transferred to a table.

For the statistical analysis, the patients with an active response (M4 or more) were considered to present a good response (Figure 3). Criteria similar to those used by the Mayo Clinic were used, as described by Carlsen et $a l^{(11)}$. The patients without an active response (M3 or less) were considered to present a poor response. We applied Fisher's exact test and took differences greater than $5 \%$ to be significant $(p=$ or greater than 0.05 ).

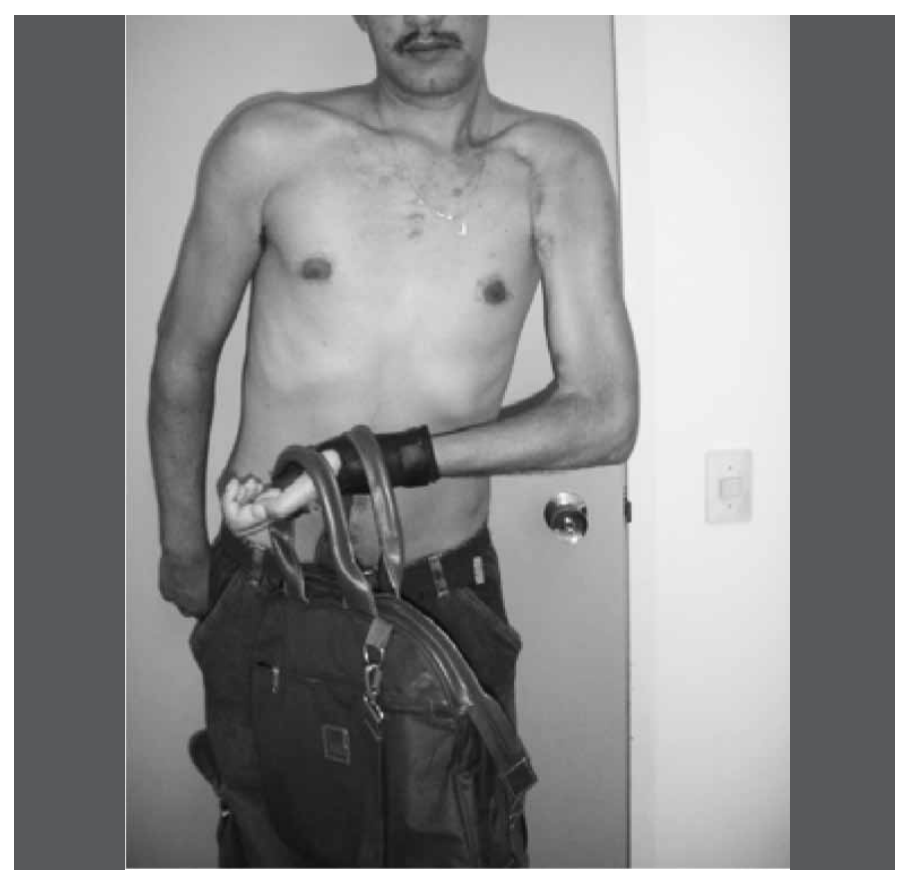

Figure 3 - Functional result in one patient.

\section{RESULTS}

All the patients were male, with a mean age of 30.8 years, ranging from 21 to 42 years. All the patients presented complete lesions of the brachial plexus, i.e. from C5 to T1, of traumatic etiology. All the cases were related to high-energy car accidents. The mean time that had elapsed between the injury and the surgical intervention was 25.7 months, with a range from 16 to 43 months. The mean duration of the outpatient follow-up was 41.5 months, with a range from six to 84 months. The complete list of patients and results can be seen in Tables 1 and 2 .

Table 1 - Analysis on group A.

\begin{tabular}{c|c|c|c|c|c}
\hline Patient' & ID & $\begin{array}{c}\text { Age } \\
\text { (in } \\
\text { years) }\end{array}$ & $\begin{array}{c}\text { Time elapsed } \\
\text { from lesion } \\
\text { to procedure } \\
\text { (in months) }\end{array}$ & $\begin{array}{c}\text { Length of } \\
\text { outpatient } \\
\text { follow-up } \\
\text { (months) }\end{array}$ & Result \\
\hline 1 & $44107880 \mathrm{~B}$ & 35 & 43 & 6 & $\mathrm{M} 0$ \\
\hline 2 & $44208700 \mathrm{G}$ & 42 & 25 & 48 & $\mathrm{M} 0$ \\
\hline 3 & $44208163 \mathrm{~J}$ & 21 & 27 & 74 & $\mathrm{M} 4$ \\
\hline 4 & $44209296 \mathrm{~K}$ & 36 & 18 & 76 & $\mathrm{M} 0$ \\
\hline
\end{tabular}

Table 2 - Analysis on group B.

\begin{tabular}{c|c|c|c|c|c}
\hline Patient & ID & $\begin{array}{c}\text { Age } \\
\text { (in } \\
\text { years) }\end{array}$ & $\begin{array}{c}\text { Time elapsed } \\
\text { from lesion } \\
\text { to procedure } \\
\text { (in months) }\end{array}$ & $\begin{array}{c}\text { Length of } \\
\text { outpatient } \\
\text { follow-up } \\
\text { (months) }\end{array}$ & Result \\
\hline 1 & $44119308 \mathrm{~K}$ & 22 & 17 & 23 & M4 \\
\hline 2 & $88215299 \mathrm{~A}$ & 40 & 25 & 7 & M0 \\
\hline 3 & $44206659 \mathrm{H}$ & 27 & 36 & 84 & M4 \\
\hline 4 & $44119035 \mathrm{~F}$ & 24 & 16 & 14 & M4 \\
\hline
\end{tabular}

Among the results obtained in group A, there were three patients with muscle strength grade M0 (75\%), i.e. an unsatisfactory outcome, and one patient with muscle strength grade M4 (25\%), i.e. satisfactory. Among the patients in group $\mathrm{B}$, there was one patient with muscle strength grade M0 (25\%), i.e. unsatisfactory, and three with muscle strength grade M4 (75\%), i.e. satisfactory.

The two groups were subjected to Fisher's exact test, using the criteria described above, and it was seen that there was a statistical difference between the results from these two groups.

\section{DISCUSSION}

One of the great limitations in treating patients with lesions of the brachial plexus is the need to perform reconstruction surgery on the peripheral nerves within one year after the occurrence of the initial trauma $a^{(1,12,13)}$.

It often occurs that many patients miss this time limit, thereby increasing the anguish of those who treat this type of pathological condition. Difficulties in the healthcare system and lack of knowledge among 
the professionals who provide attendance for these patients (who are generally victims of high-energy trauma with associated lesions in other organs or segments) are frequently indicated causes of delays in attending to patients with brachial plexus lesions.

The possibility of restoring elbow flexion, albeit seemingly little in the light of the difficulty of paralysis of the entire upper limb, makes it possible, for example, for such patients not to have to keep their arm in a sling.

The possibility of using muscle flaps for immediate skin coverage, through microsurgery techniques, stimulated the idea of carrying out functional transfers of muscles. What was missing was the nerve that would function as the donor, since in such cases, there may often be tear injuries to the roots of the brachial plexus, and thus it would not be possible to use these roots, even to reconstruct the brachial plexus, let alone to serve as a donor for transplanted muscles.

Descriptions of total or partial transfer of nerves, a tactic that has become known as neurotization, not only provide a new perspective for treating nerve lesions as such, but also signify a new possibility for reinnervating microsurgical muscle transplants ${ }^{(9)}$.

The studies by Brunelli ${ }^{(3)}$ at the beginning of the 1980s described the spinal accessory nerve, which has an origin and path outside of the brachial plexus and therefore remains uninjured in cases of tearing. This represents an important source of axons that can function as donors.

Nerve transfers to reinnervate free muscle flaps are the solution for cases that do not have nerves in their own brachial plexus for reinnervating this new muscle. Kuwae et $a l^{(14)}$ described two cases in which the gastrocnemius muscle was transferred to reestablish elbow flexion in cases of late injury of the brachial plexus.

However, the various authors are far from reaching a consensus about which nerve to use as a donor. Chung et $a l^{(9)}$ surveyed cases of muscle transplantation for restoring elbow flexion and described three groups. In the first, the musculocutaneous nerve of this site was used, in cases in which it was possible to use this nerve, but with a length of time between trauma and surgery of more than one year. It would not be possible to use this tactic on patients presenting C5 and C6 tears, for example. In the second group, branches of the intercostal nerve were used as the donor. The authors also described a third group in which the spinal accessory nerve was the donor nerve. In the four cases of this group, nerve grafts were used to maintain a suture without tension between the obturator nerve and the XI cranial pair. This group was the one with the worst functional result.

A variety of doubts relating to the technical aspects of this transfer motivated the present study. It was felt that although anastomoses performed on the thoracoabdominal branches seemed to be more difficult, they made it possible to bring the receptor nerve closer to the donor nerve, without the need to use a nerve graft. Carlsen et al ${ }^{(11)}$ studied complications in using free functional transfers from the gracilis. They described a modification to the approach, with reinsertion of the proximal extremity of the gracilis in the clavicle. This tactic made nerve transfer easier, thereby enabling direct suturing between the donor and receptor nerves. The vascular anastomosis started to be done on the thoracoacromial vessels.

Doubt still remains regarding which nerve source functions as the best donor: intercostal nerves or the spinal accessory nerve. There is still no evidence to allow it to be said that one provides a better result than the other ${ }^{(15)}$.

Like in other groups that work with this type of technique, the change in fixation site for the proximal part of the transferred gracilis was a natural evolution. There was a perception that cases fixed more distally, with the arterial anastomosis performed in the brachial artery and the consequent need to use a nerve graft interposed between the donor and receptor nerves, had worse evolution than did those with fixation performed more proximally, with the vascular anastomosis in the thoracoacromial vessel and without the need to use a nerve graft.

The aim of comparing these two groups of patients was to establish whether there was any difference in functional recovery.

With our inclusion and exclusion criteria, we ended up with a series of only a few clinical cases in this study. Nonetheless, it needs to be borne in mind that the technical demand in treating these patients is very high, and only a few centers within our setting have the capacity to undertake this type of treatment.

The results found in this retrospective study on 
this clinical series demonstrate that it was possible to reproduce the surgical tactics and attain results that were considered to be satisfactory. The patients with a complete lesion who recovered elbow flexion achieved a stable and controlled limb that did not remain in oscillation and was less of a hindrance to balance and walking.

As a natural evolution of the technique, it could be proven, albeit in a very small series, that fixation of the proximal part of the gracilis muscle in a more cranial position enables neurorrhaphy without the need for interposition of a nerve graft, with better results.

\section{CONCLUSION}

Patients undergoing microsurgical functional transfer of the gracilis muscle whose vascular anastomoses were performed in the thoracoacromial vessels presented a better functional result than did those whose anastomoses were performed in the brachial artery, with consequent use of a nerve graft.

\section{REFERENCES}

1. Azze RJ, Mattar Júnior J, Ferreira MC, Starck R, Canedo AC. Extraplexual neurotization of brachial plexus. Microsurgery. 1994;15(1):28-32.

2. Narakas A. The surgical management of brachial plexus injuries In: Daniel $\mathrm{R}$, Terzis JK, editors. Reconstructive microsurgery. Boston: Little, Brown; 1977. p. 448.

3. Brunelli GA, Brunelli GR. Preoperative assessment of the adul t plexus patient. Microsurgery. 1995;16(1):17-21.

4. Ikuta Y, Yoshioka K, Tsuge K. Free muscle graft as applied to brachial plexus injury-case report and experimental study. Ann Acad Med Singapore. 1979;8(4):454-8.

5. Doi K, Sakai K, Kuwata N, Ihara K, Kawai S. Reconstruction of finger and elbow function after complete avulsion of the brachial plexus. J Hand Surg Am. 1991;16(5):796-803.

6. Adams JE, Kircher MF, Spinner RJ, Torchia ME, Bishop AT, Shin AY. Complications and outcomes of functional free gracilis transfer in brachial plexus palsy. Acta Orthop Belg. 2009;75(1):8-13.

7. Barrie KA, Steinmann SP, Shin AY, Spinner RJ, Bishop AT. Gracilis free muscle transfer for restoration of function after complete brachial plexus avulsion. Neurosurg Focus. 2004;16(5):E8.
8. Bishop AT. Functioning free-muscle transfer for brachial plexus injury. Hand Clin. 2005;21(1):91-102.

9. Chung DC, Carver N, Wei FC. Results of functioning free muscle transplantation for elbow flexion. J Hand Surg Am. 1996;21(6):1071-7.

10. Steindler A. Operative treatment of paralytic conditions of the upper extremity. J Orthop Surg. 1919;1:608-12.

11. Carlsen BT, Bishop AT, Shin AY. Late reconstruction for brachial plexus injury. Neurosurg Clin N Am. 2009;20(1):51-64.

12. Gutowski KA, Orenstein $\mathrm{HH}$. Restoration of elbow flexion after brachial plexus injury: the role of nerve and muscle transfers. Plast Reconstr Surg. 2000;106(6):1348-57.

13. Terzis JK, Kostopoulos VK. Free Muscle Transfer in Posttraumatic Plexopathies Part II: The Elbow. Hand (N Y). 2009. doi 10.1007/s11552-009-9223-6. [Epub ahead of print]

14. Kuwae MY, Moraes FB, Oliveira E, Paranahyba R Transferência muscular livre funcional do gastrocnêmio medial em lesão do plexo braquial: relato de dois casos Rev Bras Ortop. 2007;42(1):37-40.

15. Kay S, Pinder R, Wiper J, Hart A, Jones F, Yates A. Microvascular free functioning gracilis transfer with nerve transfer to establish elbow flexion. $J$ Plast Reconstr Aesthet Surg. 2010;63(7):1142-9. 